\title{
Four types of gender bias affecting women surgeons and their cumulative impact
}

\author{
Katrina Hutchison
}

- Additional material is published online only. To view please visit the journal online (http://dx.doi.org/10.1136/ medethics-2019-105552).

\section{Correspondence to} Dr Katrina Hutchison, Department of Philosophy, Macquarie University, Sydney, NSW 2109, Australia; katrina.hutchison@mq.edu.au

Received 3 May 2019 Revised 10 December 2019 Accepted 10 December 2019 Published Online First 30 March 2020

\section{Linked}

- http://dx.doi.org/10.1136/ medethics-2019-106020 - https://doi.org/10.1136/ medethics-2020-106066

- https://doi.org/10.1136/ medethics-2020-106158

- https://doi.org/10.1136/ medethics-2020-106194

\section{Check for updates}

(c) Author(s) (or their employer(s)) 2020. No commercial re-use. See rights and permissions. Published by BMJ.

To cite: Hutchison $\mathrm{K}$.

$J$ Med Ethics

2020:46:236-241.

\section{ABSTRACT}

Women are under-represented in surgery, especially in leadership and academic roles, and face a gender pay gap. There has been little work on the role of implicit biases in women's under-representation in surgery. Nor has the impact of epistemic injustice, whereby stereotyping influences knowledge or credibility judgements, been explored. This article reports findings of a qualitative in-depth interview study with women surgeons that investigates gender biases in surgery, including subtle types of bias. The study was conducted with 46 women surgeons and trainees of the Royal Australasian College of Surgeons. Maximum variance sampling strategies ensured a comprehensive set of perspectives. Data were analysed using iterative thematic analysis to document and classify forms of gender bias experienced by the participants, including implicit bias and epistemic injustice. It found four types of bias affecting women surgeons: (1) workplace factors such as access to parental leave and role models; (2) epistemic injustices—unfair assessments of women surgeons' credibility by patients and colleagues; (3) stereotyped expectations that they will carry out more of surgery's carework, such as meeting the emotional needs of patients and (4) objectification. Implicit biases arose in each category. Given that many of the biases identified in this study are small, are harmless on their own and are not necessarily under anyone's conscious control, important questions arise regarding how they cause harm and how to address them. I draw on theoretical work on cumulative harm to answer these questions.

\section{INTRODUCTION}

Women are under-represented in surgery. ${ }^{12}$ The situation is worse in leadership and academic roles. ${ }^{34}$ Women surgeons also receive less pay on average than their male peers. ${ }^{5}$ Research into the causes of women's under-representation and low status have identified a number of macroscopic factors. These include life balancing, workload and parental leave entitlements; the availability of role models and mentors; and the impact of sexual discrimination and harassment. ${ }^{6-10}$ However, recent work on the under-representation of women in other fields finds that subtle factors such as implicit bias are also significant. ${ }^{11-15}$ Implicit biases are biases that individuals are unaware of, or not consciously able to control. ${ }^{16}$ Another form of subtle bias is epistemic injustice. Epistemic injustice occurs when stereotyping unfairly distorts judgements about an individual's expertise. ${ }^{17} 18$ Stereotypes can affect credibility, trust and authority, all of which are essential in the relationship between surgeons and their patients and colleagues. No previous research on women's surgical careers has explored the role of epistemic injustice, and few studies have attended to the impact of implicit bias. ${ }^{3} 19$

This paper reports the findings of a qualitative study designed to identify and characterise surgeryspecific forms of gender bias, with a focus on subtle biases such as implicit bias and epistemic injustice. It identifies four broad types of bias that affect women's surgical careers: workplace factors (such as climate and access to leave); epistemic injustices; role stereotypes; and experiences of objectification. Drawing on these findings, I argue that a major contributor to women's under-representation and the gender pay gap in surgery is the systemic interaction and aggregation of many small factors. I argue that existing strategies to improve the climate of surgery for women do not adequately attend to this. Drawing on theoretical resources on the ethics of moral aggregation, I indicate how this insight can inform new strategies.

\section{METHODS}

\section{Study design and participants}

An in-depth, semistructured interview study was conducted with 46 women surgeons who were either fellows of the Royal Australasian College of Surgeons (RACS) $(\mathrm{n}=38)$, or current surgical trainees within the Australian and New Zealand training systems overseen by RACS $(n=8)$. Maximum variance sampling strategies were used with an aim of recruiting surgeons from each of the nine recognised surgical specialties in Australia, and at different career stages from trainee to senior consultants, and with different perspectives on the current debate about sexual harassment and bullying in surgery. To achieve these aims, surgeons were recruited through advertisements in the RACS newsletter and social media, forums accessed widely. Advertisements were also circulated in the RACS Trainees Association newsletter, to reach all current trainees, and in the Women in Surgery Section newsletter, to reach those with particular interest in the topic. Direct approach and snowballing techniques were used to complement these approaches and ensure all target groups were represented. Full breakdown of the numbers of participants from each subspecialty and career stage are not provided due to the very small number of women in some specialties and at some career stages in Australia, and risk that these details may therefore be identifying.

\section{Data collection}

Interviews took place between May and October 2017. They were conducted at a time and location convenient to the participant, either in person, 
or over telephone or video link. Participants received information about the study by email ahead of the interview and had an opportunity to discuss the research and ask questions before providing written consent to participate. I conducted all interviews and recorded them using a digital audio recorder. Interviews lasted for an average length of $82 \mathrm{~min}$. The shortest interview was $30 \mathrm{~min}$ and the longest was $133 \mathrm{~min}$.

A set of prompts (online supplementary appendix 1) guided the interviews. These explored participants' career motivations as well as any barriers and supports to their surgical careers. The prompt guide facilitated discussion of many aspects of surgical training and careers, without pre-empting the types of experiences participants might discuss. For example, one prompt asked participants about the interpersonal dynamics involved in being a surgeon and encouraged discussion of these in relation to different groups they interacted with (such as patients, nurses and surgical colleagues). Gender bias was not explicitly mentioned in the prompts, to ensure that participants who did not find gender a relevant frame would explain their experiences in the terms that they felt appropriate, and that those who mentioned gender explicitly were doing so based on their experiences rather than in response to leading questions. For similar reasons, the prompt did not include concepts such as implicit bias, microinequity or epistemic injustice, and I did not use these terms unless the participant did.

My academic background is in empirical bioethics and philosophy, and I am experienced in conducting qualitative research with health professionals, including surgeons. Moreover, I have previously undertaken conceptual research on gender bias in women's academic careers. My approach to the interviews aimed to minimise the influence of this theoretical background, by using minimal, open-ended prompts and expressing these in neutral, non-technical language. I also avoided directive behaviour, such as teaching or counselling participants during the interview. ${ }^{20}$

\section{Data analysis}

Transcription and analysis occurred concurrently with data collection to monitor the interview technique; ensure that the findings from early interviews could inform subsequent interviews; and to identify when saturation of data occurred. A professional service undertook the transcription, and removed identifying information such as names and places from transcripts. I checked that all interviews had been de-identified, and undertook an iterative, thematic analysis of the data. ${ }^{21}$ The focus of the analysis was to comprehensively document forms of gender bias experienced by the participants, and organise these into meaningful categories that might inform the development of gender equity strategies. A research assistant provided support during the analysis, entering analysed data into the software used for data management (NVivo V.10).

\section{Research ethics}

The study had ethics approval and was designed and conducted in accordance with Australia's National Statement on Ethical Conduct in Human Research (National Health and Medical Research Council, 2007). The funder (Macquarie University) had no involvement in: the design of the study; collecting, analysing or interpreting the data; writing up the findings or deciding to submit.

\section{RESULTS}

Based on the interviews, gender biases affecting women's surgical training and careers are of four types: biases in workplace conditions; epistemic injustices; role stereotypes and experiences of objectification. Many of the instances of gender bias were subtle. Implicit gender biases occurred across all four categories.

\section{Workplace conditions}

Many participants described the impact on their careers of lack of job flexibility, long work hours and the requirement that trainees move hospital (and sometimes city) on a 6 monthly basis to complete rotations during the training (table 1). Some participants felt that these surgical work conditions disproportionately affected women due to their typically higher domestic workload and limited window for childbearing.

Opportunities and supports for career progression were another challenge identified by participants. Many emphasised the importance of role models, mentors and networks, especially

\begin{tabular}{|c|c|}
\hline Description & Representative quotes \\
\hline \multicolumn{2}{|l|}{ Work conditions } \\
\hline work-life balance & $\begin{array}{l}\text { 'I think you use up your twenties, basically exhausted, working to the exclusion of all other things. At least, that was my experience. I didn't have } \\
\text { time with my family. I didn't have time with my friends, I didn't have time for relationships, I didn't have time for extra study.' (P8) }\end{array}$ \\
\hline Lack of flexibility & $\begin{array}{l}\text { 'Certainly one of the bosses I worked for when I was first back from maternity leave was awfully hard. She didn't support at all my choices in } \\
\text { choosing to deliver naturally or breastfeed my children.' (P5) }\end{array}$ \\
\hline \multicolumn{2}{|l|}{ Career progression } \\
\hline Access to networks & $\begin{array}{l}\text { 'There's this club in surgery, and you're either in it, or you're not. You've either got the handshake and you're in the club-and that's usually if your } \\
\text { dad was a surgeon or you went to Boys' Grammar or you played rugby' (P40) }\end{array}$ \\
\hline Role models & $\begin{array}{l}\text { 'Females can be the toughest critics of other females, and I think there's multiple reasons for that, but if you look at the small number of older } \\
\text { females, they had to fit a male model to survive back in those days' (P3) }\end{array}$ \\
\hline \multicolumn{2}{|l|}{ Climate } \\
\hline Explicit sexism & $\begin{array}{l}\text { 'a female surgeon with children, they were talking about what a crap surgeon she is, and she's off having babies[...]So if you're a female trainee } \\
\text { standing there operating while the boss is talking about this, about another female consultant, of course that affects you.' (P15) }\end{array}$ \\
\hline Harassment and assault & 'I've certainly had some very inappropriate sexual approaches, though. People putting their hands in through my gowns' (P10) \\
\hline $\begin{array}{l}\text { Including low-level } \\
\text { harassment }\end{array}$ & $\begin{array}{l}\text { 'just sex jokes and things[...]anything that would make you blush when you're a medical school student[...]they try and talk to you and try and get } \\
\text { you involved in the joke, and I'd be embarrassed.' (P9) }\end{array}$ \\
\hline \multicolumn{2}{|l|}{ Work spaces } \\
\hline Change rooms & $\begin{array}{l}\text { 'you miss the opportunity in the change rooms[...]you might be in the change rooms for fifteen minutes, and so that's fifteen minutes of time with } \\
\text { your peer or supervisor that you don't otherwise get.' (P6) }\end{array}$ \\
\hline
\end{tabular}


in successfully applying for surgical training and in establishing a career after the completion of training. All participants spoke positively of the mentors and sponsors who had provided them with advice and support. Despite this, a common theme in the interviews was the scarcity of mentors and role models, particularly women. Participants perceived this as having two causes: the low absolute numbers of women in surgery; and the hardened attitudes displayed by some women who were successful. Some participants also felt excluded from powerful networks that influenced hiring decisions.

Another set of significant workplace factors involved the unfavourable climate of surgery for women. This included experiences of explicit sexism, such as disparagement of women for taking parental leave. In addition, many participants shared experiences of sexual harassment, bullying and even sexual assault from colleagues.

Most of the workplace factors identified were explicit. However, some were more subtle, including access to networks. Spatial arrangements could also have subtle, cumulative impacts on women trainees. For example, a number of women trainees described situations in which they missed out on informal training and networking that occurred in the men's change room before or after an operation.

Even where workplace factors were explicit, the impacts and harms were sometimes subtle. For example, several participants described how hearing negative comments about another female colleague affected their own confidence.

\section{Challenges to credibility}

Establishing oneself as a surgeon, developing a trusting relationship with patients and achieving an appropriate degree of authority with colleagues presented challenges to many participants (table 2). One of the most commonly described experiences was misrecognition by patients, who assumed that the woman was not a surgeon, or that she was junior to a male colleague. These instances of misrecognition force women surgeons to establish their credibility explicitly, for example, by using Dr rather than Ms as a title ('usually people would become Mister, but I've decided to stay 'Doctor', because I don't want to be Ms or Mrs.' [P9]), and introducing themselves as the consultant surgeon. Some participants emphasised the minor or harmless nature of these mistakes: 'It doesn't worry me. It's just that you have to explain it occasionally. It's public education.' (P37).

Participants described both credibility deficits and positive assumptions from patients and colleagues-expectations that they knew less or more, or that they had poorer or better skills than they in fact had. Commonly reported deficits included expectations that women surgeons would be less knowledgeable or technically less proficient, especially for procedures understood to require strength (eg, joint replacement). Positive assumptions included expectations that women would better understand matters related to female reproduction, and that women's suturing would be neater.

Some of the more nuanced sexist assumptions involved referral patterns by general practitioners (GPs). One surgeon received more varicose veins referrals and less ulcer and aneurysm referrals than her male colleagues did, despite subspecialising in aneurysms. Another participant noted that female orthopaedic surgeons are referred fewer large joint replacements such as hips and knees due to a perception that these are too physically demanding.

For participants working in private practice, the relationship between fees and credibility was a common theme. Several participants said patients believe surgeons with higher fees are better. They felt they suffer a credibility deficit for charging lower fees than male colleagues, even when their reason for doing so is the patients' financial situation. Others felt that patients expected to pay lower fees to woman surgeons.

Most of the epistemic injustices experienced by the participants involved implicit rather than explicit bias. Stereotyped credibility

\begin{tabular}{|c|c|}
\hline Description & Representative quotes \\
\hline \multicolumn{2}{|l|}{ Misrecognition } \\
\hline Mistaken as junior & 'a lot of patients will look to the more junior registrar, or the more junior house surgeon, who's a tall male, rather than look at you' (P29) \\
\hline \multicolumn{2}{|l|}{ Credibility deficits } \\
\hline Non-compliance & $\begin{array}{l}\text { 'I was telling her something —-we'd been telling her every day she had to do something, [then the male consultant] said, "You can't do this!" } \\
\text { And she goes, "Oh, OK! Thank you, Doctor.' (P9) }\end{array}$ \\
\hline Skill stereotypes & '[the nurses] were waiting for me to have to call the consultant orthopaedic surgeon in because I couldn't reduce a fracture' (P27) \\
\hline \multicolumn{2}{|l|}{ Credibility excesses } \\
\hline Reproductive health & $\begin{array}{l}\text { 'the young [pregnant] women with [terminal condition], there probably is a little bit of a bias to wanting a woman to look after them, and as } \\
\text { much as I don't have children, so I don't know quite how that works' (P11) }\end{array}$ \\
\hline \multicolumn{2}{|l|}{ Pay and credibility } \\
\hline Quality & $\begin{array}{l}\text { 'I hate coming back to money, but to me that seems like it's possibly the most objective way of saying how I think the patients see me. Are they } \\
\text { willing to pay me?' (P39) }\end{array}$ \\
\hline $\begin{array}{l}\text { Expecting women to charge } \\
\text { lower fees }\end{array}$ & $\begin{array}{l}\text { 'I've had a number of patients—I'm not a very expensive surgeon! My secretaries are very angry that I don't charge very much at all! But } \\
\text { patients going, 'But I just saw the—-she's just a female doctor. Why is that really expensive?' (P13) }\end{array}$ \\
\hline $\begin{array}{l}\text { Women's reasons for charging } \\
\text { lower fees }\end{array}$ & $\begin{array}{l}\text { 'they've had three kids who are seeing me simultaneously and I'Il charge for the first one and I'Il bulk bill for the second two, or someone's got } \\
\text { a long term problem or I can see, "Oh, my god, you've got cancer, I'm not going to charge you, you've got cancer." [...] The other day I kept } \\
\text { someone waiting more than I like to keep them waiting, so I bulk-billed them.' (P33) }\end{array}$ \\
\hline
\end{tabular}


Table 3 Role factors

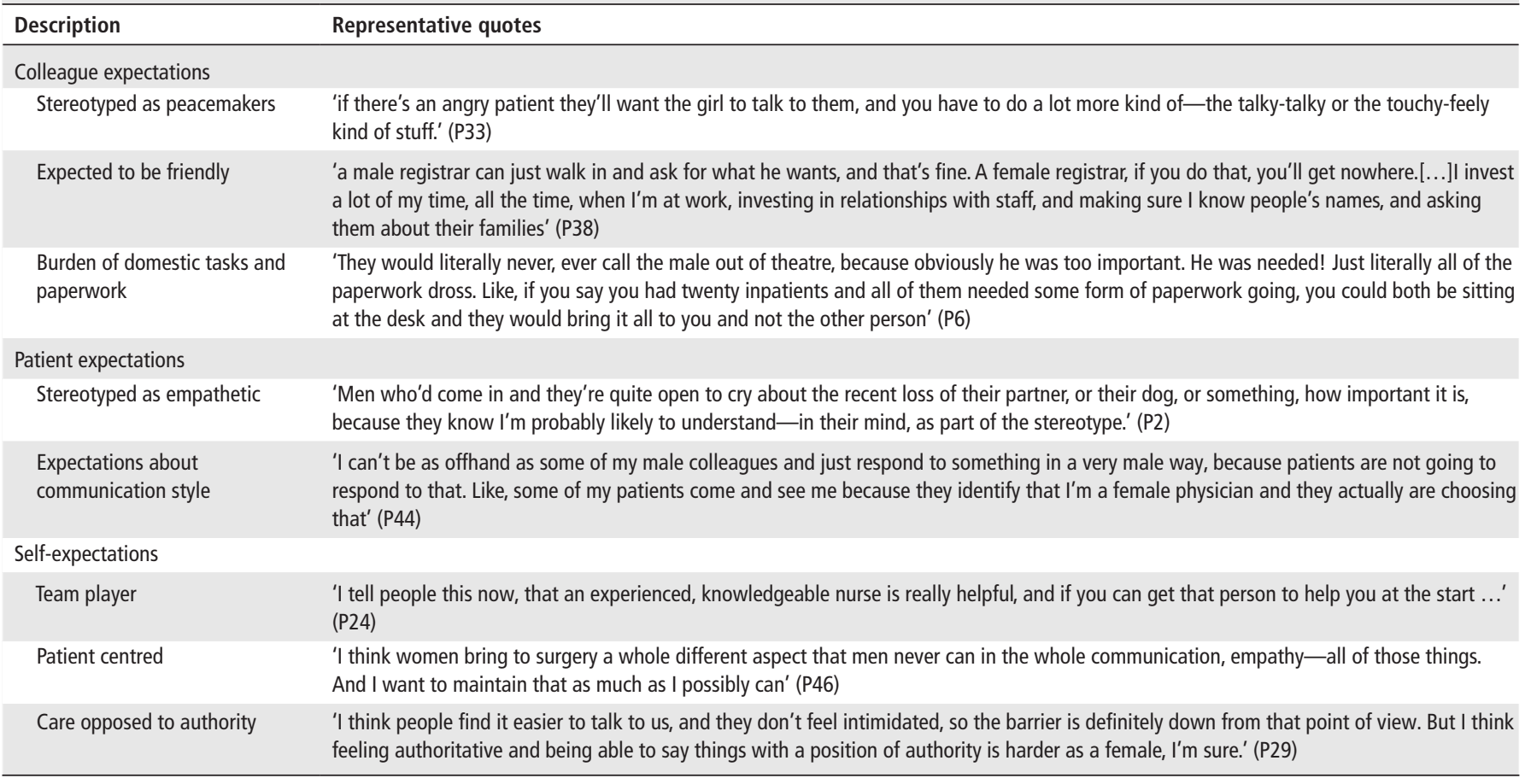

deficits and excesses were not necessarily within the awareness or control of the patient or colleague, and often there was no negative intent, as when patients compliment neat stitching.

\section{Role factors}

Many of the women surgeons interviewed for the study described expectations that they would take on peacemaking or caring duties when patients were angry, upset or anxious (table 3). In addition, women felt an expectation that they would spend more time with patients and provide better communication. In their interactions with colleagues, too, many women surgeons felt they had to be actively friendly, rather than merely polite. This was especially true of interactions with nursing staff. Participants felt that as women they did more than their share of domestic and clerical aspects of the role, including paperwork and making coffee for meetings. Not all women in the study viewed these roles as burdensome or negative, although some did. Several reflected on the tension between being caring or approachable, and being able to exercise authority. Others embraced the expectation that women be team players, cultivate friendly (not merely polite) relationships with colleagues, and take a patient-centred approach to consultations.

Like epistemic injustices, many of these role factors involve the implicit acceptance by patient or colleagues of a gendered stereotype, rather than intentional or explicit sexism.

\section{Objectification}

Participants in the study did not explicitly talk about feeling objectified by patients or colleagues. Nevertheless, in the analysis of the data, there was an emerging pattern of surgeons experiencing awareness of their physical appearance due to comments by patients and colleagues (table 4). In some cases, surgeons' strategies for establishing authority and respect involved strategically managing their physical appearance. This most often revolved

Table 4 Objectification by patients, colleagues, and self.

\begin{tabular}{|c|c|}
\hline \multicolumn{2}{|l|}{ Sexualisation } \\
\hline By colleagues & 'I've had one [specialty] consultant ask me how many people I've slept with to get on to [my specialty]' (P37) \\
\hline By patients & $\begin{array}{l}\text { 'this one man, you know, he had anal pain so I asked to examine him and he said-he started making all these weird jokes, like, 'Oh, you have to } \\
\text { buy me dinner first!' You know: 'Give me your phone number.' (P35) }\end{array}$ \\
\hline Re-establishing clinical role & $\begin{array}{l}\text { 'my strategy for dealing with those moments in my career has always been to, I guess, briefly acknowledge those considerations and move on } \\
\text { with confidence, and then I let my conduct be the driver of the patient developing respect for me.' (P38) }\end{array}$ \\
\hline \multicolumn{2}{|l|}{ Appearance } \\
\hline $\begin{array}{l}\text { Influence on surgical } \\
\text { colleagues }\end{array}$ & $\begin{array}{l}\text { 'I lost a lot of weight at one stage, and I certainly think thinner people get treated better. Thinner, more attractive women certainly get treated } \\
\text { better.' (P41) }\end{array}$ \\
\hline $\begin{array}{l}\text { Being mistaken for another } \\
\text { woman }\end{array}$ & $\begin{array}{l}\text { 'We were both sort of blonde-ish, thinnish women doing [specialty] and so people just lumped us all in together. Maybe we didn't stand out. } \\
\text { Maybe there was just this single persona of blonde-ish, thinnish women who wanted to do [that specialty]! (P11) }\end{array}$ \\
\hline \multicolumn{2}{|l|}{ Clothes } \\
\hline Power dressing for respect & $\begin{array}{l}\text { 'I found that when I go to work, I wear my heels, I wear a nice dress or a skirt, I put on my make-up, my hair's done well and I look impeccable, } \\
\text { and you get more respect.' (P13) }\end{array}$ \\
\hline $\begin{array}{l}\text { Highlight importance of } \\
\text { practical clothes. }\end{array}$ & $\begin{array}{l}\text { 'High heel shoes are not comfortable for ridiculously long shifts. So, those stereotypes, like girls take forever to put their make up on and all that } \\
\text { sort of stuff, it just doesn't work with the job.' (P42). }\end{array}$ \\
\hline
\end{tabular}


around clothing; some participants engaged in deliberate power dressing, selecting expensive suits and high-heeled shoes. Others intentionally eschewed this, selecting clothing and footwear that represented their readiness for the physical demands and potential mess of theatre.

\section{DISCUSSION}

The study provides insights into gender biases in surgery, including subtle and implicit biases. It identifies four types of gender bias that affect women's surgical careers. The first, workplace discrimination, has been previously documented in surgery. ${ }^{6-10} 2223$ Professional bodies are beginning to develop resources and training to improve workplace climate, such as the Operating with Respect campaign. ${ }^{24}$ The second type of gender bias identified-the impact of epistemic injustices on women's surgical careers-has not been previously described. It refers to harm done to someone in his or her capacity as a bearer of knowledge. Epistemic injustice may be associated with propositional (theoretical) knowledge, ${ }^{17}$ or understood more broadly to include prejudicial assumptions about hands-on knowledge or skill. ${ }^{25} 26$ The broader understanding is apt for surgery, given the importance of technical skills. The third and fourth type of gender bias are stereotyped roles and objectification. Rather than focus on each of these four types of bias separately (or their many subinstances) it is important to consider how they interact and the cumulative consequences for women surgeons.

Many of the instances of bias described in the study seem minor, and were not necessarily perceived as harmful by participants ('it doesn't worry me' [P9]). However, they do not occur in isolation, but interact and aggregate, which can be pernicious. Strategies for improving women's representation and status in the profession should recognise the risk of cumulative harm and interaction between different types of bias. A similar finding emerges from recent research into women's reasons for leaving surgical training by Liang et al, who discovered that it is usually the combined impact of several factors (eg, unavailability of leave combined with sleep deprivation and bullying) that cause trainees to withdraw from training. ${ }^{27}$ Liang et al have developed a simple but powerful 'tower of blocks' model for understanding the cumulative nature of trainees' decisions to leave surgery. Their model resonates with theoretical research in ethics on the way small factors can aggregate to form large harms that are more than the sum of their parts. ${ }^{28} 29$

Many of the forms of bias found in this study involve apparently small instances. In some cases, these are implicit. This means that the biased individuals are either unaware of their biases, or are not consciously able to control them. ${ }^{16}$ Nevertheless, participants in the study often found the small instances burdensome, as they required management and led to more general changes in work practices. For example, women modified the way they introduced themselves to patients to reduce the likelihood of mistaken identity; they developed strategies for establishing trust with patients; and they arranged appointment schedules to allow additional time for the personal and empathic communication patients would expect of them.

These small burdens can accumulate and/or interact to create harms that are more serious. Consider the cumulative impact of the following: Women surgeons tend to be referred more emotional patients who require the "talky-talky or the touchy-feely kind of stuff' (P33). They also perceive that patients in general will expect longer consultations with more personal communication and empathy. Many women surgeons have incorporated additional patter into their consultations to correct possible errors on the part of patients, such as introducing themselves more fully and carefully. They also take pains to build trust and respect with patients, in view of possible objectification or uncertainty patients may feel with a women surgeon. These features of women's clinical practice combine to make their consultations longer. The study findings suggest that women do not receive higher pay for these longer consultations. In fact, participants in the study were more likely to express concern about the capacity of patients to pay, and to offer discounted fees, than to charge more for a long consultation. One participant even described reducing her fees for a patient she had kept waiting, suggesting that in some cases longer consultations might cost women surgeons money.

These cumulative harms take on a more troubling note when combined with the gendered patterns of credibility or epistemic injustices. The aspects of surgery in which women experience credibility excesses, and in which they are encouraged to excel by positive reinforcement and higher training load, are materially undervalued. Building a practice around long, affordable consultations and providing patient-centred care is likely to mean accepting a lower income. The other option is to resist these expectations. However, women who work in areas of surgery stereotyped as more masculine encounter other barriers, such as gendered referral patterns from GPs. Moreover, the findings suggest that being (seen to be) caring, empathetic and approachable is in direct tension with being credible and holding authority. One participant articulated this explicitly: 'I think people find it easier to talk to us, and they don't feel intimidated, so the barrier is definitely down from that point of view. But I think feeling authoritative and being able to say things with a position of authority is harder as a female' (P29).

The gender biases revealed by this study thus appear to cause harm at two levels. The individual biased acts can be harmful (as when a women is irritated by having to explain to a patient that she is the surgeon), and multiple instances can give rise to harm of a different type (as when the strategies women develop due to common biases cause longer consultations). Kahn has described these emergent harms as 'essentially aggregative'. ${ }^{30}$

Elsewhere I have identified three features of aggregative harms: their systemic nature, the (relative) invisibility of the forces that give rise to them, and the expedience of practices that support them. ${ }^{29}$ All three factors are present in the case of gender biases affecting women surgeons. The instances of subtle gender bias are often invisible to perpetrators, such as patients who do not realise that they have misidentified the senior surgeon in the room. Moreover, the way these biases accumulate and interact is not obvious. Expedience supports at least some of the factors. Biased GP referral patterns are likely to be expedient: in Australia, GPs come to know of local specialist surgeons informally through processes such as advertising, and via their networks from medical school. The lack of information about available specialists encourages reliance on stereotypes. In general, stereotypes support energy saving, and thus expedient, decision making. ${ }^{31}$

Aggregative harms tend to emerge in the context of complex systems, especially informal systems of practice involving many loosely connected individuals and institutions. This is true in the context of women's surgical careers: women surgeons in Australia work in private and/or public hospitals. They are (usually) fellows of RACS, and members of organisations representing their specialty group, such as the Australian Orthopaedic Association. Their training occurs in multiple hospitals. They interact with patients, patient families, nurses and allied health professionals as well as medical and surgical colleagues. The gender biases described in this research emerge within this complex, multidimensional system. 
Addressing aggregative harm requires understanding the functioning of the system from which it emerges, making the harms and the way they aggregate visible, and challenging expedient practices that support them. ${ }^{29}$ In this case, the process of making visible requires research aimed at identifying small or unexpected sources of bias (like this study, or the study by Liang et al). ${ }^{27}$ Understanding the role that expedient processes play in aggregative harm can help support the case for replacing cheap or fast processes with less efficient but fairer ones. For example, justifying the cost of developing and maintaining a platform to help GPs find specialists based on accurate information.

Perhaps most importantly, understanding that aggregative harms emerge from systems can inform interventions that focus on the nature of the system rather than the individuals within it. In particular, identifying influential nodes within the system and targeting interventions at these. In this case, it would be effective to focus on surgical training programmes. Surgical training is often overseen at the national level (this is true in Australia, where it is overseen by RACS). The training programme, thus, influences all new surgeons entering the system in a country, as well as all the surgical supervisors and hospitals involved in the provision of training. The types of bias identified in the results section indicate problem areas that training programmes should address, for example, ensuring fair distribution of emotionally needy patients between male and female trainees.

\section{Strengths and limitations of the study}

A strength of the study is the large number of participants interviewed for a study of this type, and the breadth of career stages and surgical specialty groups represented. This ensures the results offer a wide view of the types of gender bias experienced by women surgeons. It was also clear during the interviews and analysis of the data that the participants held a range of perspectives on the topic of gender bias in surgery, as well as whether too little or too much was already being done to support women surgeons. This study type is not apt for quantitative analysis of the extent and distribution of gender bias across women surgeons due to the recruitment strategy. Maximum variance sampling typically over-represents members of some groups and under-represents others in order to take account of the widest possible range of experiences. Follow-on research is needed to explore the extent and distribution of these biases. Moreover, the study does not provide information about how the experiences of women surgeons differ from those of men, given that men were not interviewed. Follow-on research with both genders is needed to provide this comparative perspective.

I have offered only a general indication of the types of intervention that can disrupt processes of cumulative harms, and a few examples based on the study findings. Due to limited space I do not offer a comprehensive set of recommendations applying this approach to all findings of the study.

Acknowledgements Thanks to Wendy Carlton for assistance with the analysis of the data.

Contributors $\mathrm{KH}$ is the sole author.

Funding The study was funded by a Macquarie University Research Fellowship (MQRF) 'Gender in Surgery: An Exploration of Biases Affecting Surgeons, Trainees and Patients' (2016-2019). MQRF Award ID: 63989874.

Competing interests $\mathrm{KH}$ reports non-financial support (travel and conference registration) from the Royal Australasian College of Surgeons (RACS) to present a paper at the RACS Annual Scientific Congress in 2017.

Patient consent for publication Not required.

Ethics approval The study was approved by the Macquarie University Human Research Ethics Committee (Approval \# 5201700117).
Provenance and peer review Not commissioned; externally peer reviewed.

Data availability statement Data are available upon request. However, this availability is conditional on the ability to protect participant identity and adherence to conditions of the research ethics approval.

\section{ORCID iD}

Katrina Hutchison http://orcid.org/0000-0002-5817-7488

\section{REFERENCES}

1 Royal Australasian College of Surgeons. Activities report, 2016. Available: https:// www.surgeons.org/media/25115804/racs-activities-report-2016.pdf [Accessed 15/12/2018].

2 Royal College of Surgeons. Women surgeon statistics, 2017. Available: https://www. rcseng.ac.uk/careers-in-surgery/women-in-surgery/mission-and-goals/womensurgeon-statistics/ [Accessed 15/12/2018].

3 Cochran A, Hauschild T, Elder WB, et al. Perceived gender-based barriers to careers in academic surgery. Am J Surg 2013;206(2):263-8.

4 Zhuge Y, Kaufman J, Simeone DM, et al. Is there still a glass ceiling for women in academic surgery? Ann Surg 2011;253(4):637-43.

5 Savona B. Gender pay gaps revealed: the jobs where there's a huge difference between male and female incomes. Available: https://www.smartcompany.com.au/ people-human-resources/gender-pay-gap-jobs-difference-male-female-incomes/ [Accessed 10 Dec 2018].

6 Park J, Minor S, Taylor RA, et al. Why are women deterred from general surgery training? Am J Surg 2005;190(1):141-6.

7 Hoover EL. Mentoring women in academic surgery: overcoming institutional barriers to success. J Natl Med Assoc 2006;98(9):1542-5.

8 Saunders CM, Nichevich A, Elllis C. Frontiers in academic surgery: the five M'S. Aust N Z J Surg 2008:78(5):350-5.

9 Turner PL, Lumpkins K, Gabre J, et al. Pregnancy among women surgeons: trends over time. Arch Surg 2012;147(5):474-9.

10 Fitzgerald JEF, Tang S-W, Ravindra P, et al. Gender-Related perceptions of careers in surgery among new medical graduates: results of a cross-sectional study. Am J Surg 2013;206(1):112-9.

11 Rowe M. Micro-affirmations and micro-inequities. J Int Ombudsman Assoc 2008; $1(1): 45-8$.

12 Hutchison K, Jenkins F. Women in philosophy: What needs to change. New York: Oxford University Press, 2013.

13 Levinson JD, Young D. Implicit gender bias in the legal profession: an empirical study. Duke Journal of Gender Law and Policy 2010;18(1):1-44.

14 Roos PA, Gatta ML, Gender GML. Gender (in)equity in the academy: Subtle mechanisms and the production of inequality. Res Soc Stratif Mobil 2009;27(3):177-200

15 Goldin C, Rouse C. Orchestrating Impartiality: The Impact of "Blind" Auditions on Female Musicians. Am Econ Rev 2000;90(4):715-41.

16 Brownstein M, Saul JM. Implicit bias and philosophy: metaphysics and epistemology. Oxford: Oxford University Press, 2016.

17 Fricker M. Epistemic injustice: power and the ethics of knowing. Oxford: Oxford University Press, 2007.

18 Kidd IJ, Medina J, Pohlhaus G. The Routledge Handbook of Epistemic injustice. Routledge, Abingdon and New York, 2017.

19 Phillips NA, Tannan SC, Kalliainen LK. Understanding and overcoming implicit gender bias in plastic surgery. Plast Reconstr Surg 2016;138(5):1111-6.

20 Britten N. Qualitative research: qualitative interviews in medical research. BMJ 1995;311(6999):251-3.

21 Liamputtong P. Qualitative research methods. 4th edn. Oxford: University Press, Oxford, 2013.

22 Ardnell Group. A study exploring the reasons for and experiences of leaving surgical training. Final report, 2016. Available: https://www.surgeons.org/media/25492594/ ardnell-report.pdf [Accessed 24 Jan 2019].

23 Parle G, Parle J. Independent prevalence survey on discrimination, bullying and sexual harassment: summary of facts. commissioned by the Royal Australasian College of surgeons, 2015. Available: https://www.surgeons.org/media/22045682/ PrevalenceSurvey Summary-of-Facts FINAL.pdf [Accessed 24 Jan 2019].

24 Royal Australasian College of Surgeons. About respect: addressing bullying and Harrassment. Available: https://www.surgeons.org/about-respect/ [Accessed 8/1/2019].

25 Shotwell A. Forms of knowing and epistemic resources. In: The Routledge Handbook of Epistemic injustice. Abingdon and New York: Routledge, 2017.

26 Hawley K. Knowing how and epistemic injustice. In: Knowing how: essays on knowledge, mind, and action. Oxford: University Press, Oxford, 2011.

27 Liang R, Dornan T, Nestel D. Why do women leave surgical training? A qualitative and feminist study. Lancet 2019;393(10171):541-9.

28 Brennan S. Moral lumps. Ethical Theory and Moral Practice 2006;9(3):249-63.

29 Hutchison K. Gender bias in medical implant design and use: a type of moral aggregation problem? Hypatia 2019;34(3):570-91.

$30 \mathrm{Kahn} \mathrm{E}$. The tragedy of the commons as an essentially aggregative harm. J App/ Philos 2014;31(3):223-36.

31 Macrae CN, Milne AB, Bodenhausen GV. Stereotypes as energy-saving devices: a peek inside the cognitive toolbox. J Pers Soc Psychol 1994;66(1):37-47. 